\title{
Study on Corrosion of Zinc Metal in Acid Environment
}

\author{
Chang-shan HUANG, Jin-ying WU, Ming DING, Hui-wu XU*, Min ZHANG, \\ Min CHEN, Mian XUE, Xiao-guang ZHANG, Ke-ping TIAN
}

Institute of Energy Research, Henan Academy of Science, No. 29 Garden Road,

Zhengzhou R. P. China, 450008

E-mail: 13937140170@163.com

\begin{abstract}
Keywords: Acid environment; organic compounds; zinc; corrosion inhibitor.
Abstract. The experiment was carried out in the acidic conditions to test three kinds of organic compounds, the cetyltrimethyl ammonium bromide (CTAB), nicotinic acid and bromohexadecyl pyridine on the corrosion inhibition performance of metal Zinc by means of the experiment and testing methods of the static rotary coupon test, electrochemical polarization and SEM (Scanning Electron Microscope). The purpose is to study a kind of compound organic corrosion inhibitor which has the best inhibition effects on the metal Zinc. The static coupon experiment showed that the weight loss ratio of metal Zinc specimens was relatively small in CTAB and bromohexadecyl pyridine composition and the weight loss ratio of metal Zinc specimens was relatively large in the nicotinic acid composition. The electrochemical polarization test result showed that CTAB, nicotinic acid and bromohexadecyl pyridine can induce the shifting of the corrosion potential of metal Zinc $\left(\mathrm{E}_{0}\right)$ in the acidic environment. SEM showed that CTAB and bromohexadecyl pyridine composition formed a uniform and compact film on the metal Zinc surface. The conclusion can be drawn that CTAB, nicotinic acid and bromohexadecyl pyridine can be combined with one another in the acidic conditions. Among them, the CTAB and bromohexadecyl pyridine composition has a good inhibition effect on the corrosion of metal Zinc in that it forms a uniform and compact film on the surface of metal Zinc.
\end{abstract}

\section{Introduction}

Zinc is commonly used in numerous industries and fields. It is often used as a sacrificial metal in coatings to protect other metals, particularly ferrous metals. The galvanized metals used in water-circulating systems often produce white rust, so the method of prevention of removal of corrosion is important ${ }^{[1-3]}$. Investigation into the corrosion tendencies of zinc can lead to important applications in production and economics. The use of inhibitors is one of the most practical methods by which to protect zinc from corrosion, particularly in acidic mediums ${ }^{[4-13]}$. Organic inhibitors with electron-donating groups such as nitrogen, sulphur and oxygen often play an important role in zinc corrosion prevention ${ }^{[14-19]}$.

The present work investigates the effects three organic compounds on the corrosion inhibition of zinc in $0.5 \mathrm{M}$ hydrochloric acid: cetyltrimethyl ammonium bromide (CTAB), nicotinic acid and bromohexadecyl pyridine. $\mathrm{CTAB}$ is a cationic surface active agent; nicotinic acid and bromohexadecyl pyridine are heterocyclic compounds. The effect of single inhibitor concentration on the anticorrosion efficient was investigated, as well as the anticorrosion efficiencies of CTAB, nicotinic acid and bromohexadecyl pyridin.

\section{ExperImental Methods}

Materials. CTAB(Tianjin Guangfu Fine Chemical Research insitute, AR); nicotinic acid(Tianjin kemi'ou Chemical Reagent Co., Ltd. AR); bromohexadecyl pyridine(Tianjin Guangfu Fine Chemical Research insitute, AR); hydrochloric acid(Tianjin Guangfu Fine Chemical Research insitute, AR).

Inhibitors Prepared. The following inhibitors were prepared for experimental analysis: 
1) $4.0 \mathrm{~g}$ of CTAB were dissolved at $70{ }^{\circ} \mathrm{C}$. A volume of $100 \mathrm{ml}$ was set aside for experimental use.

2) $1.5 \mathrm{~g}$ of bromohexadecyl pyridine were disoolved at $50{ }^{\circ} \mathrm{C}$. A volume of $250 \mathrm{ml}$ was set aside for experimental use.

3) $4.0 \mathrm{~g}$ of acid were dissolved at $40{ }^{\circ} \mathrm{C}$. A volume of $250 \mathrm{ml}$ was set aside for later use. Inhibitor solutions were then prepared according to the following mixtures:

Compound 1: CTAB $200 \mathrm{mg} . \mathrm{L}^{-1}$ nicotinic acid $100 \mathrm{mg} . \mathrm{L}^{-1}$ and bromohexadecyl pyridine $60 \mathrm{mg} . \mathrm{L}^{-1}$. Compound 2: CTAB $20 \mathrm{mg} . \mathrm{L}^{-1}$ and bromohexadecyl pyridine $60 \mathrm{mg} . \mathrm{L}^{-1}$.

Instruments. Potentiostat/galvanostat CS2305, JSM-6510; scanning electron microscopy(SEM), BT224S Electronic Balance.

\section{Experimental Procedure}

Weightloss Test of Zinc. The corrosion of zinc after exposure to inhibition solutions was evaluated according to the static hanging piece test, reference HG/T2387-2007. The corrosion inhibition test was conducted at $25^{\circ} \mathrm{C}$ for 96 hours in a testing solution of $0.5 \mathrm{M}$ hydrochloric acid. The experimental solution was comprised of $0.5 \mathrm{M} \mathrm{HCl}$ and inhibitor solution. The corrosion rate was calculated according to the following formula:

$$
K=\frac{W_{1}-W_{2}}{S \cdot T}
$$

Where $K$ is the corrosion rate, $\mathrm{g} \cdot \mathrm{m}^{-2} \cdot \mathrm{h}^{-1} ; W_{l}$ is the weight of the zinc plate before the test, $\mathrm{g} ; W_{2}$ is the weight of the zinc plate after the test, $\mathrm{g} ; S$ is the initial area of the plate, $\mathrm{m}^{2}$; and $T$ is the time elapsed during the experiment, $\mathrm{h}$.

Electrochemical Test of Zinc. Zinc electrodes were sealed in epoxy resin, except for an exposed cross-section at the working surface with an area of $1 \mathrm{~cm}^{2}$. The counter electrode for the electrochemical test was made of platinum, while a saturated calomel electrode (SCE) was used as the reference electrode. The electrochemical studies were conducted on the potentiostat/galvanostat CS2305. Linear polarization measurement were conducted with a potential perturbation of $\pm 100 \mathrm{mV}$ around the open circuit potential (OCP). The electrolyte was prepared by adding various concentrations of different inhibitors to $0.5 \mathrm{M}$ hydrochloric acid solution.

SEM Test. The zinc plates were observed on SEM JSM6510 after testing. The operation parameters were set to $20 \mathrm{kV}$ acceleration voltage.

\section{Results And Discussion}

Corrosion Test Results. Figure 1(a) displays the corrosion rates of zinc after exposure to various concentrations of CTAB inhibitor solutions. Results indicate that the introduction of CTAB (in the experimental range $0 \mathrm{mg} . \mathrm{L}^{-1} \sim 600 \mathrm{mg} . \mathrm{L}^{-1}$ ) can protect zinc immersed in $0.5 \mathrm{M} \mathrm{HCl}$ from corrosion. The corrosion rate of zinc in $0.5 \mathrm{M} \mathrm{HCl}$ solution is $17.5 \times 10^{-4} \mathrm{~g} \cdot \mathrm{m}^{-2} \cdot \mathrm{h}^{-1}$, while the corrosion rate of zinc in $0.5 \mathrm{M} \mathrm{HCl}$ in the presence of CTAB is reduced to below $6.6 \times 10^{-4} \mathrm{~g} \cdot \mathrm{m}^{-2} \cdot \mathrm{h}^{-1}$. Increases in CTAB concentration does not significantly alter the rate of zinc corrosion in $\mathrm{HCl}$. Figure1(b) displays the corrosion rate of zinc in various concentrations of nicotinic acid inhibitor solutions. Results indicate that the nicotinic acid (in the experimental range $160 \mathrm{mg} . \mathrm{L}^{-1} \sim 480 \mathrm{mg} . \mathrm{L}^{-1}$ ) does not significantly alter the corrosion rate of zinc in $\mathrm{HCl}$. When the concentration of nicotinic acid was $300 \mathrm{mg} . \mathrm{L}^{-1}$, the corrosion rate $\left(20.4 \times 10^{-4} \mathrm{~g} \cdot \mathrm{m}^{-2} \cdot \mathrm{h}^{-1}\right)$ is higher than that observed in $0.5 \mathrm{~m} \mathrm{HCl}\left(17.5 \times 10^{-4} \mathrm{~g} \cdot \mathrm{m}^{-2} \cdot \mathrm{h}^{-1}\right)$. When the concentration of nicotinic acid is $480 \mathrm{mg} . \mathrm{L}^{-1}$ the corrosion rate is $14.01 \mathrm{~g} \cdot \mathrm{m}^{-2} \cdot \mathrm{h}^{-1}$, which does not meet industrial requirements. Figure 1(c) displays the corrosion rate of zinc in various concentrations of bromohexadecyl pyridine inhibitor solution. Results indicate that the introduction of bromohexadecyl pyridine to $0.5 \mathrm{M} \mathrm{HCl}$ solution can protect zinc from corrosion. The corrosion rate of zinc in $0.5 \mathrm{M} \mathrm{HCl}$ solution decreases with increasing bromohexadecyl pyridine concentrations. 
When the bromohexadecyl pyridine concentration is $100 \mathrm{mg} \cdot \mathrm{L}^{-1}$, the corrosion rate of zinc is $2.17 \times 10^{-4} \mathrm{~g} \cdot \mathrm{m}^{-2} \cdot \mathrm{h}^{-1}$. Figure 1(d) depicts the anti-corrosion efficiency of inhibitor mixtures in relation to zinc corrosion. Results indicate that compound 1, consisting of CTAB, nicotinic acid and bromohexadecyl pyridine, is more effective than any single inhibitor. The corrosion rate of zinc in $\mathrm{HCl}$ in the presence of compound 1 is $3.2 \times 10^{-4} \mathrm{~g} \cdot \mathrm{m}^{-2} \cdot \mathrm{h}^{-1}$. Additionally, a mixture of CTAB and bromohexadecyl pyridine without nicotinic acid is more effective than compound 1 and any single inhibitor.
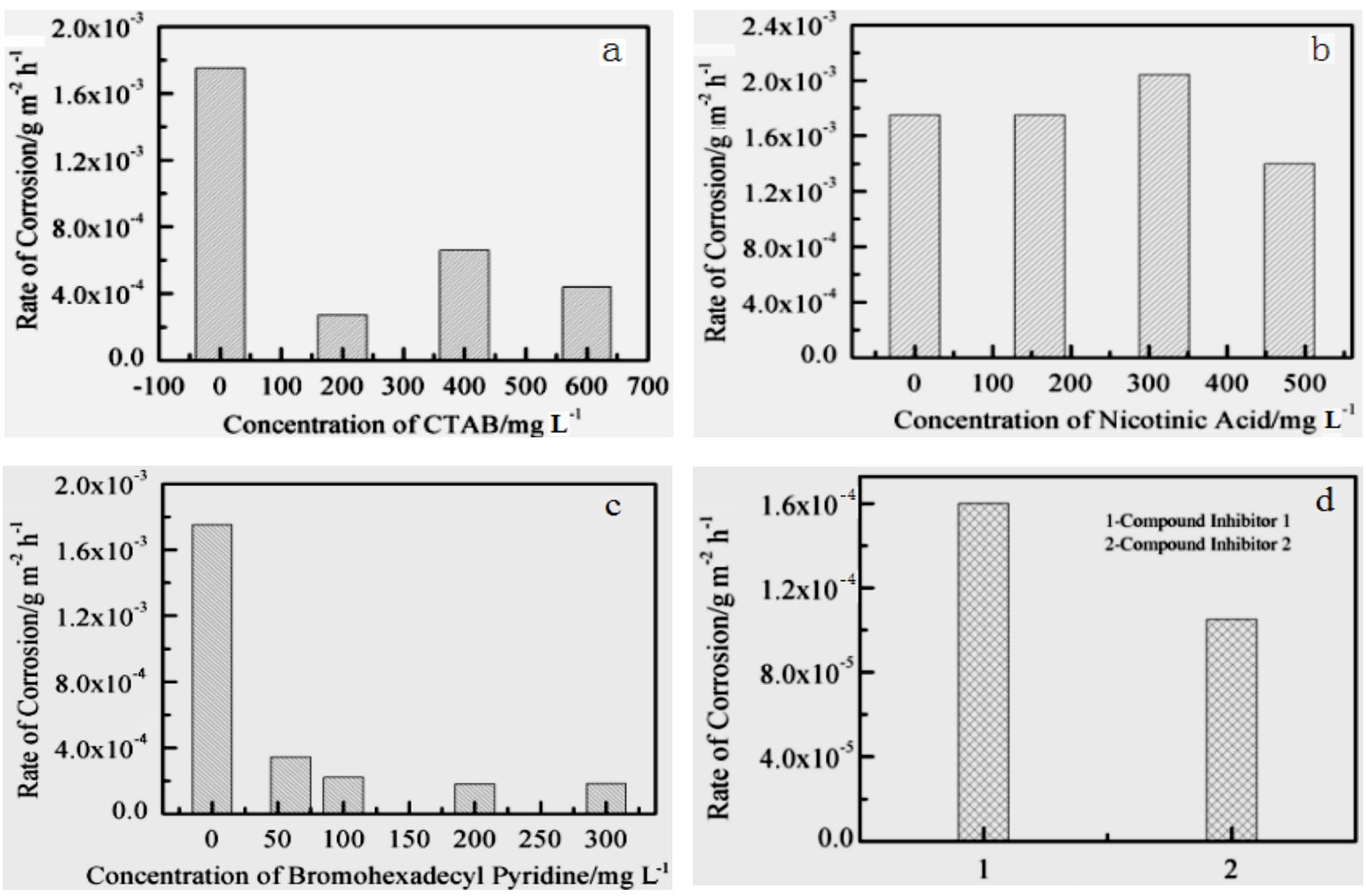

Fig. 1. Corrosion rate of zinc in varying concentrations of inhibitor solutions (a) CTAB; (b) nicotinic acid; (c) bromohexadecyl pyridine; (d)compound

Electrochemical Test Results. Table 1 displays the $\mathrm{E}_{0}$ of zinc in the presence of various inhibitor solutions, obtained from Tafel fitting results. As shown in Table 1, the change of $\mathrm{E}_{0}$ in the presence of CTAB and bromohexadecyl pyridine solutions is irregular with variations in inhibitor concentrations, while the change of $\mathrm{E}_{0}$ in nicotic acid solution is regular. The addition of CTAB nicotinic acid and bromohexadecyl pyridine all induce a positive shift in $\mathrm{E}_{0}$ values. As shown in Table 2, the $\mathrm{I}_{0}$ of zinc indicates better anti-corrosion performance correlated to smaller values in different inhibitor solutions results indicate that the tendency of $\mathrm{I}_{0}$ changes in the presence of CTAB is similar to changes in the presence of $\mathrm{HCl}$ alone.

Table $1 \mathrm{E}_{0}$ of zinc in various inhibitor solutions

\begin{tabular}{|c|c|c|c|c|c|}
\hline CTAB & $\mathrm{E}_{0}[\mathrm{~V}]$ & Nicotinic acid & $\mathrm{E}_{0}[\mathrm{~V}]$ & $\begin{array}{c}\text { Bromohexad } \\
\text { ecyl pyridine }\end{array}$ & $\mathrm{E}_{0}[\mathrm{~V}]$ \\
\hline 0 & -1.0384 & 0 & -1.0384 & 0 & -1.0384 \\
\hline 200 & -1.0027 & 160 & -0.9960 & 60 & -0.9695 \\
\hline 400 & -1.0112 & 320 & -0.9931 & 100 & -0.9829 \\
\hline 600 & -1.0224 & 480 & -0.9760 & 200 & -0.9822 \\
\hline 800 & -1.0111 & & & 300 & -0.9791 \\
\hline \multicolumn{6}{|c|}{ Compound 1 } \\
\hline
\end{tabular}


Table $2 \mathrm{I}_{0}$ of zinc in various inhibitor solutions

\begin{tabular}{|c|c|c|c|c|c|}
\hline CTAB & $\mathrm{I}_{0}\left[\mathrm{~A} \cdot \mathrm{cm}^{-2}\right]$ & Nicotinic acid & $\mathrm{I}_{0}\left[\mathrm{~A} \cdot \mathrm{cm}^{-2}\right]$ & $\begin{array}{l}\text { Bromohexad } \\
\text { ecyl pyridine }\end{array}$ & $\mathrm{I}_{0}\left[\mathrm{~A} \cdot \mathrm{cm}^{-2}\right]$ \\
\hline 0 & $6.8 \times 10^{-4}$ & 0 & $6.8 \times 10^{-4}$ & 0 & $6.8 \times 10^{-4}$ \\
\hline 200 & $5.7 \times 10^{-4}$ & 160 & $6.9 \times 10^{-4}$ & 60 & $1.2 \times 10^{-4}$ \\
\hline 400 & $2.4 \times 10^{-3}$ & 320 & $4.3 \times 10^{-4}$ & 100 & $1.7 \times 10^{-4}$ \\
\hline 600 & $6.4 \times 10^{-4}$ & 480 & $5.3 \times 10^{-4}$ & 200 & $1.2 \times 10^{-4}$ \\
\hline 800 & $2.8 \times 10^{-3}$ & & & 300 & $1.0 \times 10^{-4}$ \\
\hline \multicolumn{3}{|c|}{ Compound 1} & $4.0 \times 10^{-4}$ & Compound 2 & $3.9 \times 10^{-5}$ \\
\hline
\end{tabular}

The change in $\mathrm{I}_{0}$ in the presence of nicotinic acid concentration is not significant, while the $\mathrm{I}_{0}$ of zinc in inhibitor solutions is smaller than in the presence $0.5 \mathrm{~m} \mathrm{HCl}$ alone.

Figure 2 shows the polarization curves of zinc in various inhibitor solutions. Results indicate that the introduction of CTAB, nicotinic acid and bromohexadecyl pyridine causes significant alteration in the cathode curve. Inhibitor compouns 1 and 2 cause obvious changes in anode and cathode reactions. The changes in open potential and cathode reaction may be caused by the film formed by the compound solution of CTAB, nicotinic acid, and bromohexadecyl pyridine.
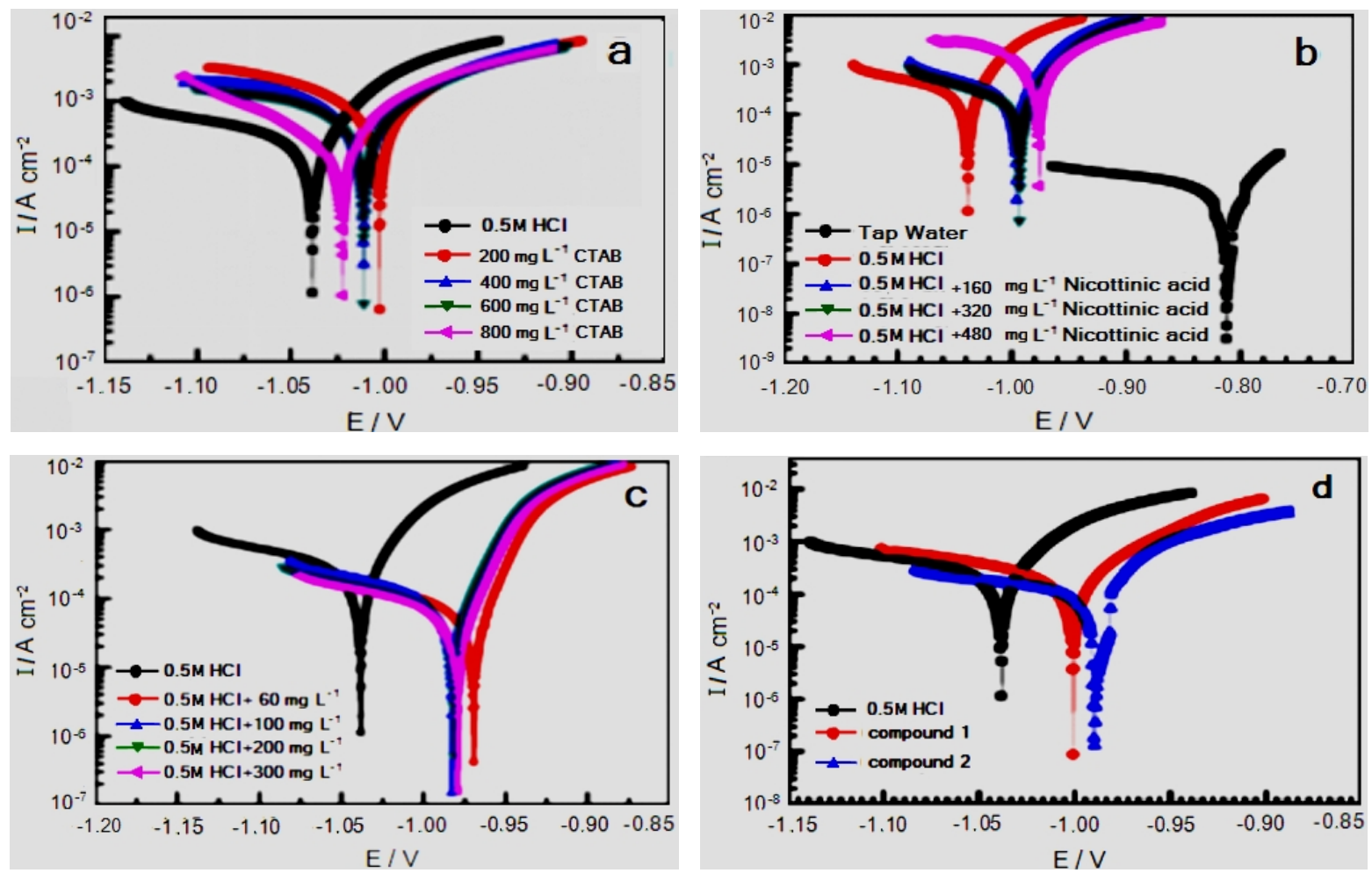

Fig. 2. Polarization curves of zinc in (a) CTAB solution; (b) nicotinic acid; (c) bromohexadecyl pyridine and (d) inhibitor compounds

In summary, the corrosion and electrochemical test results indicated that compound 2 demonstrates better anti-corrosion performance than any other tested compound or single inhibitor solution.

Results of SEM test. Figure 3 depicts SEM photos of zinc after exposure to different inhibitor solutions in $\mathrm{HCl}$ for 96 hours at $25^{\circ} \mathrm{C}$. Figure 3(a) demonstrates microcosmic scratches on the surface of the zinc. Figure $3(\mathrm{~b})$ shows that when zinc is immersed in $0.5 \mathrm{M} \mathrm{HCl}$, a large number of corrosion pits formed on the surface of the zinc. The presence of CTAB in Figure 3(c), nicotinic acid in Figure 
3(d) and bromohexadecyl pyridine in Figure 3(e) can form a uniform and compact film that prevents zinc from corrosion in the presence of $\mathrm{HCl}$. And zinc in inhibitor compounds in Figure 3 (f).

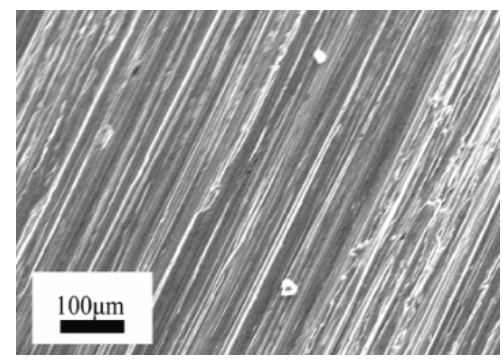

(a)

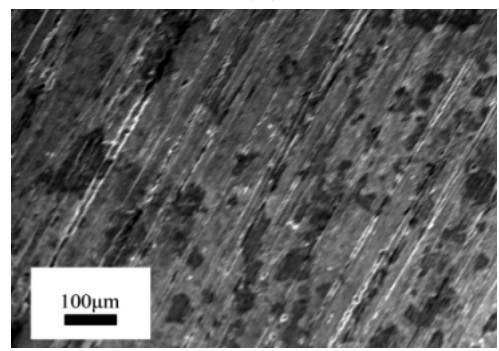

(d)

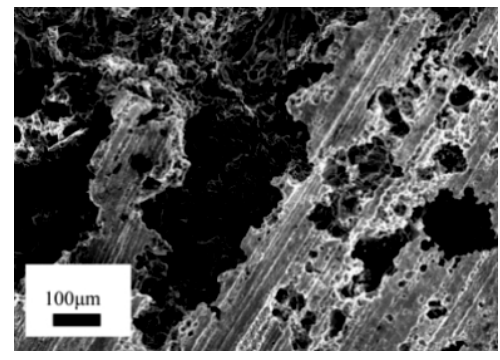

(b)

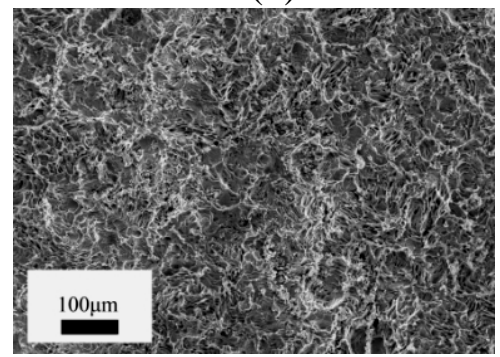

(e)

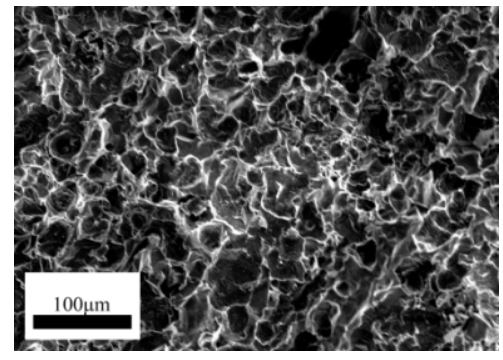

(c)

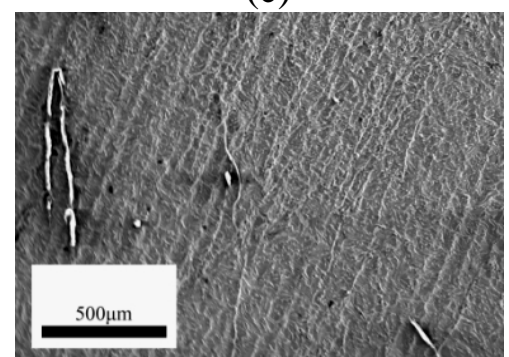

(f)

Fig. 3. SEM photos of (a) pure zinc; (b) zinc in $0.5 \mathrm{M} \mathrm{HCl}$; (c) zinc in CTAB solution; (d) zinc in nicotinic acid solution; (e) zinc in bromohexadecyl pyridine solution; and (f) zinc in inhibitor compounds

Figure 4(a) (b) depicts photos of zinc plate immersed in $0.5 \mathrm{M} \mathrm{HCl}$ alone and $0.5 \mathrm{M} \mathrm{HCl}$ in the presence of compound 2 inhibitor solutions for 96 hours at $25^{\circ} \mathrm{C}$. The results indicate the formation of a macroscopic film on the zinc plate.

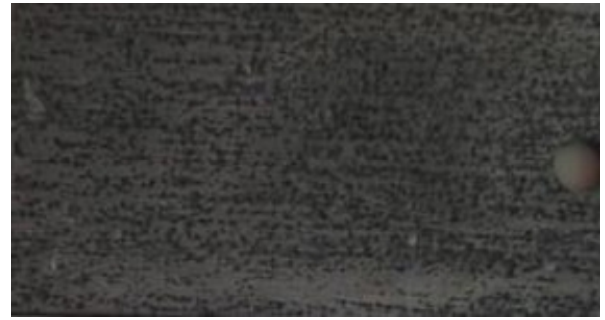

(a)

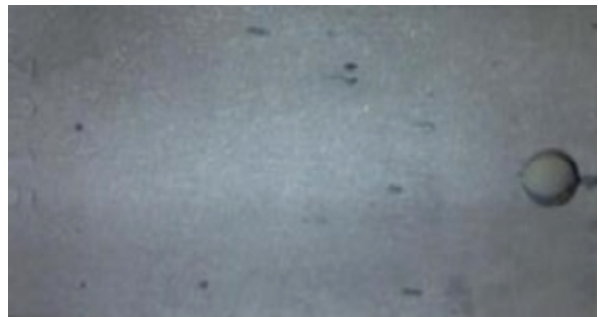

(b)

Fig. 4. Photos of zinc in (a) $0.5 \mathrm{~m} \mathrm{HCl}$; (b) inhibitor compound solutions

\section{Conclusion}

1. Weight loss results indicate that $\mathrm{CTAB}$ and bromohexadecyl pyridine can protect zinc from corrosion in the presence of $\mathrm{HCl}$. The weight loss does not alter markedly with increasing concentrations of either inhibitor. The introduction of nicotinic acid displayed no effect on zinc corrosion.

2. Polarization and SEM results indicate that CTAB and bromohexadecyl pyridine form a compact and uniform membrane on the surface of zinc.

3. The weight loss tendency of zinc in the presence of various inhibitors result in similar $\mathrm{I}_{0}$ values, which indicates the anti-corrosion performance of inhibitor solutions in reference to zinc. 


\section{Acknowledgements}

This work was financially supported by Henan province science and technology development public relations plan(182102311000), Innovative Development Project of Henan Academy of Sciences(18ZS06015).

\section{References}

[1] ZHANG Kuo, DU Min: Equipment Environmental Engineering, 13(5) (2016), p.140

[2] TU Sheng, TANG Qi, LI Chuan-qiang, Fine Chem., 32(4)(2015), p. 451

[3] M. Abdalah., Corros. Sci., 45 (2003), p. 2705

[4] A. G. Gadallah, H. M. oustafa, J. Appl. Electrochem,, 22(1992), p. 644

[5] M.S. Morad, J. Appl. Electrochem., 29 (1999), p. 619

[6] D. S. Zhang, L. D. Li, L. X. Cao, etal., Corros. Sci., 43 (2001), p.1627

[7] S. Manov, A. M. Lamazouere, L Aries, Corros. Sci., 42 (2000), p. 1235

[8] K. Aramaki, Corros. sci., 43(2001), p. 1985

[9] Y. K. Agrawal, J. D. Talati, M. D. Shah,etal., Corros.Sci., 46(2004), p. 633

[10] Y. Ein-eli, M. Auinat and D. Starosvetsky, J. Power sources, 114 (2003), p. 330

[11] J. Dobryszycki, S.Biallozor, Corros. Sci., 43(2001), p1309

[12] SUN Cai-Xia , HUANG Chang-shan, WU Jin-Ying, etal., Henan Sci., 34(11)(2016), p. 1822

[13] RONDLA R, CHING-KUAN L, JUNG-TANG L, etal., J. Chin. Chem. Soc., 60(2013), p. 21

[14] LIU Jing, ZHAO Di-shun, LI Jing-jing, etal., Corrosion \& Protection, 37(12)(2016), p. 983

[15] LOTO R T, LOTO C A, FEDOTOVA T., Res. Chem. Intermed, 40(4) (2014), p. 1501

[16] MEI Y, KATHRIN S, ANJA-VERENA M., Mater Chem. C, 2(2014), p. 458

[17] ZHAO Bin, JIAO Qing-zhu, HE Miao, etal., Cleaning world, 31(1) (2015), p. 25

[18] LIU Yu-wei, WANG Zhen-yao, Equipment Environmental Engineering, 12(4) (2015), p. 22

[19] FENG Xiao-juan, SHI Yan-long, WANG Xing-yi, Chem. World, 56(7) (2015), p. 428 